\title{
OBSERVACIONES SOBRE EL COMPORTAMIENTO REPRODUCTIVO DEL PAICHE, Arapaima gigas, EN CAUTIVERIO
}

\author{
ALCANTARA BOCANEGRA FERNANDO ( $\left.{ }^{*}\right)$
}

\section{RESUMEN}

El paiche, A rapaima gigas (Cuvier, 1829), se reproduce en cautiverio. Una pareja alcanzó su primera maduración a los seis años de edad y luego tuvo reproducción anual durante dos años consecutivos. En promedio se obtuvieron 40 crías por cada período anual de reproducción.

La pareja protegió a su prole desde el momento del desove hasta que las crías alcanzaron una longitud promedio de $45 \mathrm{~cm}$., en que fueron separadas de los progenitores. La especie protegió a su prole activamente, embistiendo a quiénes se aproximaban al estanque de reproducción.

PALABRAS CLAVES: Edad de primera reproducción. Comportamiento reproductivo en cautiverio. paiche, A rapaima gigas.

\section{INTRODUCCION}

El paiche, A rapaima gigas (Cuvier, 1829), es uno de los mayores peces de la amazonía peruana. Por la excelente calidad de su carne se le utiliza en el consumo humano en forma tradicional, sustentándose el abastecimiento, fundamentalmente, en las capturas que se realizan en la Reserva Nacional Pacaya-Samiria, sub-cuenca hidrográfica interna entre los ríos M arañón y U cayali. 
Los estudios de la especie están referidos mayormente a observaciones en el medio natural, entre ellos destacan los de historia natural, ecología y aprovechamiento de SANCHEZ (1960), estudio del factor de condición de BERGER (1972) y estudio del desarrollo sexual y ciclo de maduración de GUERRA (1980).

En esta investigación, se reporta la edad de primera maduración de una pareja de paiches, el número promedio de crías por reproducción y el comportamiento reproductivo en cautiverio.

\section{MATERIAL Y METODOS}

Las observaciones se efectuaron en Iquitos, en el período comprendido entre 1985, 1986 y 1987, utilizando un estanque de 3,000 m2, con profundidades variables entre $0.60 \mathrm{~m}$. y $1.20 \mathrm{~m}$. Este estanque formaba parte del laboratorio del Instituto del Mar del Perú (IMARPE), transferido en 1987 al ms' 'uto de Investigaciones de la A maionía Peruana (IIAP).

El agua del estanque fue de color marrón oscuro, correspodiendo a la categoría de "agua negra", según la tipificación de SIP' 1 (GEISLEF et al. 1973)

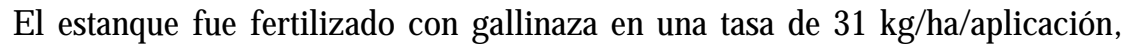
con tres aplicaciones/semana. Durante el período de observación, la fertilización se efectuó para favorecer la producción de alimento de los cíclidos nativos Cichlassoma bimaculatum y A equidens sp., especies conocidas localmente como "bufurquis', que sirvieron como alimento a los paiches.

En el estanque se introdujo una pareja de paiches que fueron criados en cautiverio a partir de la talla de $18 \mathrm{~cm}$., la misma que tenían cuando fueron capturados en la Reserva Nacional Pacaya-Samiria, a la edad aproximada de 2 meses. Desde su captura fueron alimentados con trozos de pescado fresco hasta que alcanzaron una longitud promedio de $35 \mathrm{~cm}$. y $730 \mathrm{gr}$. En ese momento se sembraron en el estanque de cultivo, cuando tenían cuatro meses de captura.

\section{RESULTADOS Y DISCUSION}

La pareja de paiches alcanzó su primera reproducción a la edad de seis años. A esa edad el ejemplar más robusto presentó una longitud de $160 \mathrm{~cm}$.; su 
coloración fue intensa, presentando el cuerpo un color general negruzco, con presencia de escamas de color rojo ladrillo en la cola y parte del vientre. De acuerdo a COPALRA y MONTALVO (1972), se trataría del macho, aunque GUERRA (1980), señala que no existe diferencia de sexos por la coloración.

El ejemplar más pequeño presentó una longitud de $145 \mathrm{~cm}$. y su coloración fue igual pero, menos intensa, presentando escamas de tonalidad rosada en la cola y parte del vientre.

L as longitudes observadas en ambos ejemplares son menores que la longitud de primera maduración del paiche de $185 \mathrm{~cm}$., reportada por GUERRA (1980, op cit), lo que se considera como casos marginales.

La pareja tuvo una reproducción anual en .tres años consecutivos, entre los meses de enero a marzo. En cada ocasión se separaron 35, 45 y 40 crías, con $45 \mathrm{~cm}$. y $845 \mathrm{gr}$. de longitud y peso promedio. La separa ión de las crías se efectuó con fines de cultivo, en el instante en que se observaron signos de dispersión del cardumen y disminución de la agresividad de los progenitores. En ese momento se observaron algunas crías con lesiones en el cuerpo, producidas posiblemente por los predadores, lo que explicaría el reducido número capturado. Entre los predadores naturales se

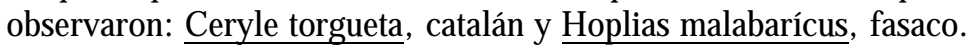

La observación de la reproducción de la pareja se efectuó en cada una de las ocasiones, en el momento en que los alevinos empezaron a emerger, produciendo en la superficie del agua del estanque un burbujeo de $10 \mathrm{~cm}$. de diámetro que permanecía unos dos segundos. Se detectó en ese momento que uno de los progenitores permanecía debajo del cardumen y emergía posteriormente para respirar

En la primera reproducción, se efectuó una captura de alevinos con una red de mano provista de una vara larga, verificándose que los ejemplares tenían una longitud promedio de $2.5 \mathrm{~cm}$. y presentaban aún vestigios del saco vitelínico.

Las observaciones de los alevinos y de los reproductores fueron dificultadas por el comportamiento agresivo que presentó en cada evento uno (le los reproductores. En tanto un ejemplar permanecía ron los alevinos, el otro cuidaba su territorio (un área que abarcaba la mitad del estanque), llegando a efectuar embestidas ruidosas contra las personas que se encontraban en las orillas del mismo. Algunas veces, este ejemplar llegó a elevarse por lo menos 0.5 metros sobre la superficie del estanque, produciendo un fuerte ruido, acompañado de la expulsión de una buena cantidad de agua que era arrojada sobre los intrusos. 
Este comportamiento agresivo fue maximizado en una ocasión, en que llegó a quitar de las manos una red de fitoplancton a un ayudante que operaba desde el monje del estanque.

El comportamiento agresivo observado fue atenuándose a medida que se reducía la dispersión del cardumen, esto es, a los seis meses de edad, momento en que se capturaron las crías.

\section{BIBLIOGRAFIA}

BERGER, Ch. 1972. Estudio del factor de condición del paiche Arapaima gigas (Cuvier) en la Zona Reservada del Río Pacaya, entre los años 1959 a 1969. Tesis Bach. Cienc. Biol. UNM SM. Lima-Perú.

COPAIRA, M. y CESAR MONTALVO. 1972. Dimorfismo sexual en el paiche (A rapaima gigas, Cuvier, 1829). Rey. mv. Pes. (IVITA), (2) 203-207. UN M SM de Lima.

GEISLER, R.; HA. KNOPPEL and 1-1. SIOLI. 1973. The Ecology of Freshwater Fishes in A mazonia. Present status and Future Tasks for Research. In Applied Sciences and Development, Institute for Scientific Cooperation.Tübingen, Rep. Fed. de A lemania Vol. 2. pág. 144-62.

GUERRA, H. 1980. Desarrollo sexual del paiche, A rapaima gigas, en las Zonas Reservadas del Estado (Ríos Pacaya y Samiria) 1971-1975. Inf. № 67. Inst. Mar del Perú. Callao. Perú.

SANCHEZ, J. 1960. El paiche. Aspectos de su historia natural, ecología y aprovechamiento. Pesca y Caza № 10. pág. 17-63. 